\title{
ANALYSIS OF TUMOUR LENGTH AND CLINICOPATHOLOGICAL FEATURES IN CARCINOMA OESOPHAGUS
}

\author{
Pampanagouda Somalapura1 ${ }^{1}$, Sailaja Suryadevara², Veerendrakumar Kariyanakatte Veeraiah ${ }^{3}$ \\ ${ }^{1}$ Consultant Surgical Oncologist, Department of Surgical Oncology, Kidwai Memorial Institute of Oncology, Bengaluru. \\ ${ }^{2}$ Consultant Surgical Oncologist, Department of Surgical Oncology, Vijayawada. \\ 3 Professor, Department of Surgical Oncology, Kidwai Memorial Institute of Oncology, Bengaluru.
}

\section{ABSTRACT}

Even with multidisciplinary team approach, the prognosis of Oesophageal Cancer (EC) has not significantly changed. Studies are required to explore the other prognostic factors, which might alter the outcome. Our study aims at correlating the oesophageal tumour length with stage of the disease and analyse the clinicopathological features.

\section{METHODS}

150 patients with oesophageal carcinoma (ca) who underwent curative surgery without neoadjuvant chemotherapy and/or radiotherapy are included in the study. Formalin fixed oesophageal tumour length was measured. Tumour length was analysed with respect to overall stage, $\mathrm{T}$ stage and $\mathrm{N}$ stage of the disease. Clinicopathological characteristics were studied.

\section{RESULTS}

From our study correlating tumour length with stage and lymph node involvement, it is observed that there is no linear association with stage of the disease. Squamous cell carcinoma is the predominant histology and lower third was the site most affected. Even though most of the patients still present at an advanced stage, patients with adenocarcinoma presented earlier than squamous cell carcinoma patients.

\section{CONCLUSION}

As there is no proportionate increase in stage of disease with increase in length of tumour, oesophageal tumour length may not be an appropriate prognostic factor. Further well planned studies might bring more evidence on this aspect with respect to im pact of tumour length on survival.

\section{KEYWORDS}

Oesophageal Carcinoma, Tumour Length.

HOW TO CITE THIS ARTICLE: Somalapura P, Suryadevara S, Veeraiah VK. Analysis of tumour length and clinicopathological features in carcinoma oesophagus. J. Evolution Med. Dent. Sci. 2016;5(49):3145-3148, DOI: 10.14260/jemds/2016/730

\section{INTRODUCTION}

Oesophageal cancer is one of the malignancy associated with poor prognosis. Oesophageal carcinoma is the $7^{\text {th }}$ most common cancer and $6^{\text {th }}$ most common cause of cancer death worldwide. ${ }^{1}$ Most of the patients in developing world still present at an advanced stage. Incidence of cancer oesophagus has increased because of the change in lifestyle and adenocarcinoma has become the predominant pathology in the western world and most are located in the distal oesophagus. Squamous cell carcinoma, which is more common in proximal and middle part of oesophagus remains the most common histology worldwide. Five-year survival rate for localized (T1, T2, T3), Regional (T4, N+), Distant (M1) metastasis is $40 \%, 21 \%$ and $4 \%$ respectively. Overall, $18 \%$ of patients will survive for 5 years or more. ${ }^{2}$ Patients with adenocarcinoma have better prognosis than squamous cell cancer. ${ }^{3}$ There are many studies to know the prognostic factors for cancer oesophagus.

Tumour length was considered as one of the prognostic factor, but later it was removed from the staging system as a

Financial or Other, Competing Interest: None.

Submission 26-04-2016, Peer Review 26-05-2016,

Acceptance 02-06-2016, Published 18-06-2016.

Corresponding Author:

Dr. Pampanagouda Somalapura,

$139,5^{\text {th }}$ Cross, $9^{\text {th }}$ Block,

Vinayaka Layout,

Nagarabhavi, Bengaluru-560072.

E-mail: drpampanagouda@yahoo.co.in

DOI: $10.14260 /$ jemds $/ 2016 / 730$ prognostic factor. Oesophageal tumour length is still a controversial prognostic factor in oesophageal carcinoma. We tried to correlate the oesophageal tumour length with stage of the disease to know whether it still holds good as a prognostic factor and analysed the clinicopathological characteristics of oesophageal carcinoma patients.

\section{METHODS}

Retrospectively medical records of 150 carcinoma oesophagus patients who were admitted at our regional cancer centre for management were reviewed (Table 1). Patients who underwent curative surgery were included. Patients who received neoadjuvant treatment or whose histopathology report of resected specimen did not have tumour length mentioned were not included. Standard Staging workup of patients done to know the extent of local disease and distant metastasis. Disease staging done according to 7 th edition of American Joint Committee on Cancer (AJCC), Tumour Node Metastasis (TNM) staging system. ${ }^{4}$ (Figure 5). Histological details along with tumour length measured with hand held ruler on the formalin fixed oesophageal resected specimen obtained from pathology reports. Tumour length ranged from 1.5 to $10 \mathrm{~cm}$ and the median tumour length was $4 \mathrm{~cm}$.

\section{RESULTS}

Male-to-female ratio was 90:60 with a median age group of 55 years (Range 30-78 years). Of these 150 patients, 29\% of patients had disease at the middle third, $44 \%$ at the lower third, and $27 \%$ at the oesophagogastric junction. Squamous 
cell carcinoma was diagnosed in $85 \%$ (127) of patients and adenocarcinoma in $15 \%$ (23) of patients. Patients with tumour length of $4 \mathrm{~cm}$ or less had $4 \%$ T1 lesions, $17 \%$ T2 lesions, $36 \%$ T3 lesions and 5\% T4 lesions. Patients with tumour length of more than $4 \mathrm{~cm}$ had no T1 lesions, but had 7\% T2 lesions, $29 \%$ T3 lesions and 2\% T4 lesions (Figure 1). Among patients with tumour length of $4 \mathrm{~cm}$ or less, $5 \%$ were in stage I, $25 \%$ in stage II, $32 \%$ in stage III. In patients with tumour length more than $4 \mathrm{~cm}$ group $2 \%$ of patients presented in stage I, $21 \%$ in stage II and 15\% in stage III (Figure 2 and Table 2). More number of patients presented with lymph node positivity among patients with tumour length of $4 \mathrm{~cm}$ or less (34\%) compared to patients with tumour length of more than $4 \mathrm{~cm} \mathrm{(17 \% )} \mathrm{(Figure} \mathrm{3).}$

Female patients $(55 \%)$ presented earlier than male patients (51\%). When analysed for squamous cell ca and adeno ca separately, similar results were observed with respect to tumour length and stage of the disease. More number of patients presented in stage III (47\%) compared to stage I (7\%) and stage II (46\%). Lymph node involvement $(34 \%)$ is more in patients with tumour length of $4 \mathrm{~cm}$ or less compared to more than $4 \mathrm{~cm}$.

Limitations of our study include the use of retrospective data, study used the data from single institution with different surgeons and pathologists and without proper follow-up of patients.

\begin{tabular}{|c|c|}
\hline Variable & Number of Patients \\
\hline Total number of pts. & 150 \\
\hline Male & 90 \\
\hline Female & 60 \\
\hline Median age & 55 (range $30-78$ yrs.) \\
\hline \multicolumn{2}{|l|}{ Location of Tumour } \\
\hline $\mathrm{M} / 3^{\mathrm{rd}}$ & 43 (29\%) (Sq-91\%, Ad -9\%) \\
\hline $\mathrm{L} / 3^{\mathrm{rd}}$ & $66(44 \%)(\mathrm{Sq}-90 \%, \mathrm{Ad}-10 \%)$ \\
\hline EG Jn & $41(27 \%)(\mathrm{Sq}-59 \%, \mathrm{Ad}-41 \%)$ \\
\hline \multicolumn{2}{|l|}{ Surgical Procedure } \\
\hline THE & $132(88 \%)$ \\
\hline TTE & $18(12 \%)$ \\
\hline \multicolumn{2}{|l|}{ Histology } \\
\hline Squamous cell ca & $127(85 \%)$ \\
\hline Adeno ca & $23(15 \%)$ \\
\hline \multicolumn{2}{|l|}{ Tumour Length } \\
\hline$</=4 \mathrm{~cm}$ & $93(62 \%)$ \\
\hline$>4 \mathrm{~cm}$ & 57 (38\%) \\
\hline \multicolumn{2}{|l|}{ T status } \\
\hline T1 & $6(4 \%)$ \\
\hline $\mathrm{t} 2$ & $36(24 \%)$ \\
\hline T3 & $97(65 \%)$ \\
\hline \multicolumn{2}{|l|}{ Lymph Node Status } \\
\hline N0 & $75(50 \%)$ \\
\hline N1 & $39(26 \%)$ \\
\hline N2 & $26(17 \%)$ \\
\hline N3 & $10(7 \%)$ \\
\hline \multicolumn{2}{|l|}{ Grade } \\
\hline $\mathrm{I}$ & $7(5 \%)$ \\
\hline II & $76(50.6 \%)$ \\
\hline III & $67(44.6 \%)$ \\
\hline $\begin{array}{r}\text { Table 1: Den } \\
\text { of th }\end{array}$ & $\begin{array}{l}\text { raphic Characteristics } \\
\text { udy Population }\end{array}$ \\
\hline
\end{tabular}

(Sq- Squamous cell ca, Ad- Adenocarcinoma, EG JnOesophagogastric Junction)

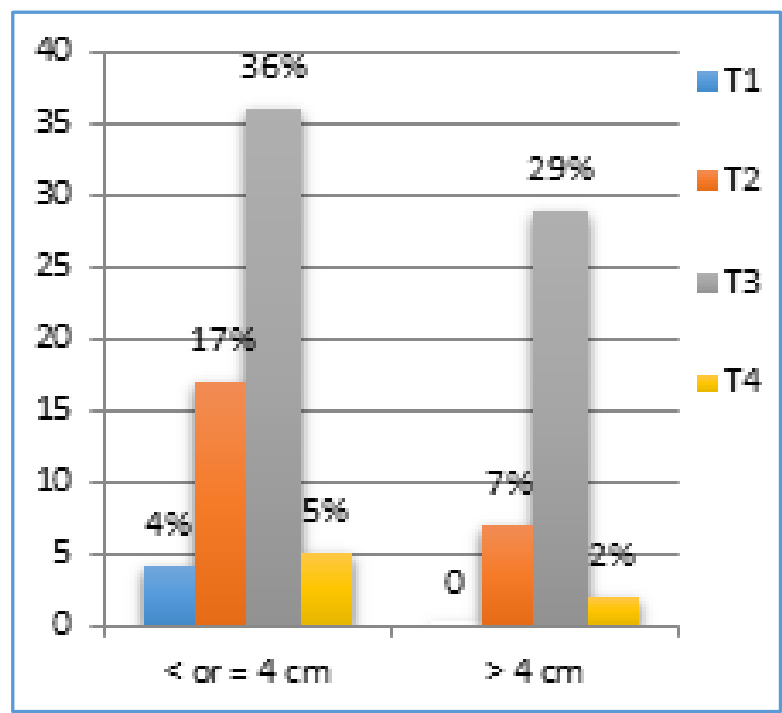

Fig. 1: Correlation of Tumour Length with T Status

\begin{tabular}{|c|c|c|c|}
\hline Stage & $</=\mathbf{4} \mathbf{~ c m}$ & $>\mathbf{4} \mathbf{~ c m}$ & P value \\
\hline I & $7(5 \%)$ & $2(2 \%)$ & 0.06 \\
\hline II & $38(25 \%)$ & $32(21 \%)$ & 0.25 \\
\hline III & $48(32 \%)$ & $23(15 \%)$ & 0.02 \\
\hline \multicolumn{4}{|c|}{$\begin{array}{c}\text { Table 2: Statistical Significance of } \\
\text { Tumour Length with Stage }\end{array}$} \\
\hline
\end{tabular}

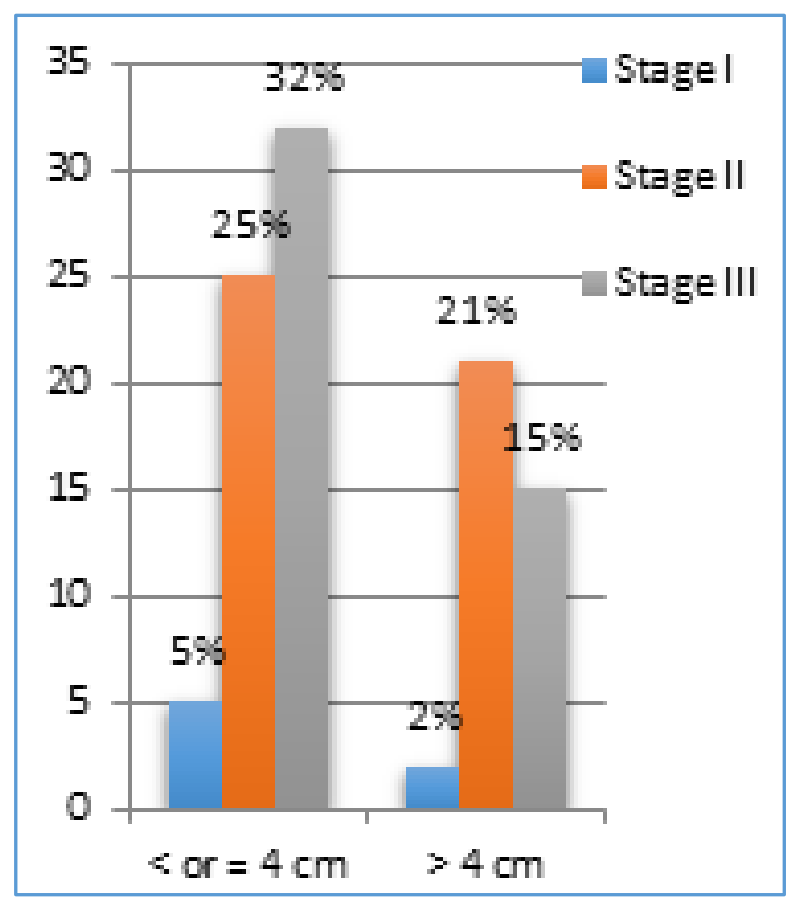

Fig. 2: Correlation of Tumour Length with Stage 


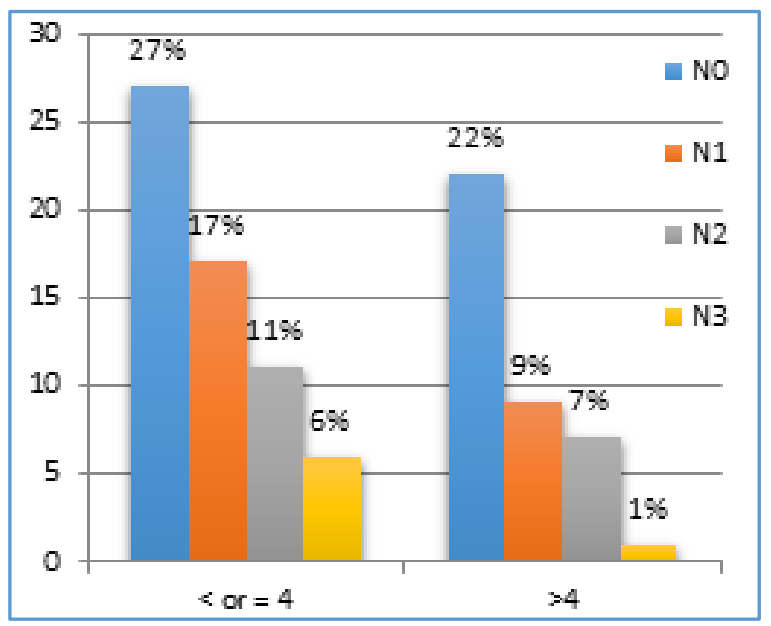

Fig. 3: Correlation of Tumour Length with Lymph Node Status

\section{DISCUSSION}

Tumour length can be assessed with oesophagoscopy (Figure 4), barium swallow study, computed tomography, endoscopic ultrasonography and histopathological examination of resected specimen.

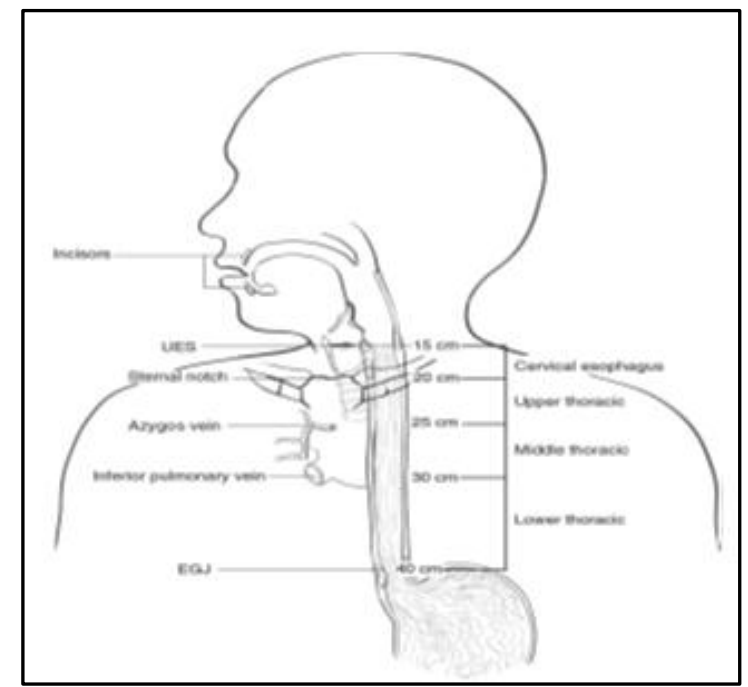

Fig. 4: Anatomy of Oesophageal Cancer Primary Site including Typical Endoscopic Measurements of Each Region Measured from the Incisors 4

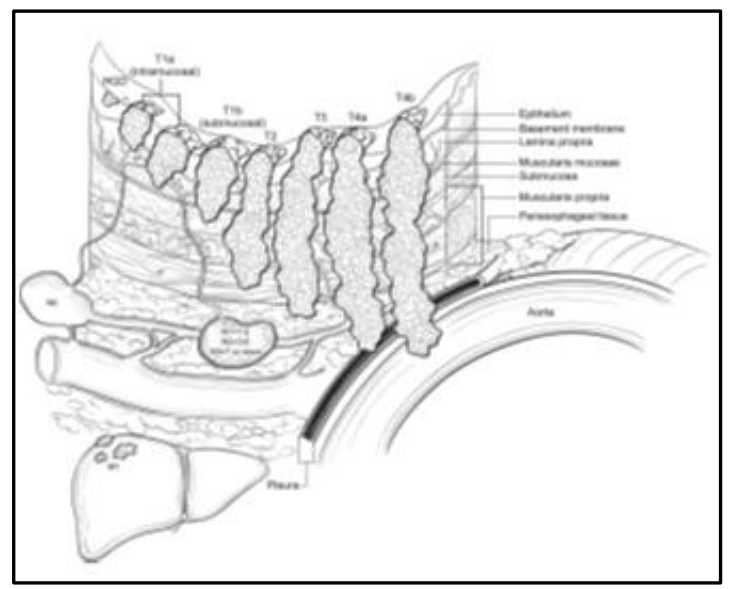

Fig. 5: T, $N$ and M Classifications. Primary Tumour (T) is Classified by Depth of Tumour Invasion. Regional Lymph Node (LN) Classifications are Determined by Metastatic Burden. Distant Metastatic Sites Are Designated M1 4
As ours is a referral centre, majority of the patients would have got the oesophagoscopy done before referral and were done by different endoscopists without accuracy about the actual length of the tumour. Hence, we considered length of resected tumour specimen for assessment. Even on stratifying according to histopathology, tumour length did not show any correlation to stage of the disease. Possibly, this can be explained by mucosal-limited carcinoma very seldom leads to LN metastasis regardless of histologic type. ${ }^{5}$

Some of the studies have shown the importance of oesophageal tumour length as a prognostic factor. When endoscopically measured tumour length in predicting overall survival in patients with oesophageal adenocarcinoma was analysed, endoscopic tumour length was identified as an independent predictor of long-term survival. ${ }^{6}$ Study by Arife Zeybek et al, to know the significance of tumour length as prognostic factor for oesophageal cancer, revealed patients with tumour length of more than or equal to $3 \mathrm{~cm}$ had highly significant difference in involvement of adventitia and lymph node stations, and patients with lesser tumour length had lower rates of involvement of adventitia and lymph nodes. ${ }^{7}$ Another study showed increased tumour length as determined by endoscopy associated with the advanced stage of disease and bad prognosis with effect largely influenced in the stage I group of patients. ${ }^{8}$

Patients with tumour length of $3 \mathrm{~cm}$ or less had improved 5-year survival compared to patients with longer tumour length. ${ }^{9}$ When prognostic significance of tumour length was analysed in the group of T1, T2 disease, 5-year survival was not affected by tumour length; however, in the T3-T4 group 5year survival was better in patients with tumour length of less than or equal to $4 \mathrm{~cm} .^{10}$ Tumour length was significant prognostic factor with improved five-year survival in patients with tumour length of $4 \mathrm{~cm}$ or less.11,12 With varying results observed, there is clearly a lack of defined definite role of tumour length as a prognostic factor in oesophageal carcinoma. A higher lymphatic spread follows a higher rate of submucosal-invading carcinomas in the early Squamous cell carcinoma group compared with the adenocarcinoma.

Submucosal tumour invasion is more often seen in patients with Squamous cell cancers compared to adenocarcinoma. 5 Hence better prognosis observed with adenocarcinoma compared to squamous cell carcinoma since LN metastasis is one of the most crucial factors affecting prognosis. Lymph node metastases may already be present in up to $10 \%$ of patients with mucosal cancer and up to $50 \%$ of patients with submucosal invasion. ${ }^{5}$ Adaptation of good lifestyle with more frequent usage of oesophagoscopy for dyspeptic symptoms might reduce the number of patients presenting at an advanced stage.

\section{CONCLUSION}

Among various studies done to assess the importance of tumour length, there is no uniformity about the effect of tumour length on prognosis of the disease with different results. In contrary to the expected increase in stage of disease with increase in tumour length, our study did not show any correlation between tumour length and stage of the disease. Hence, tumour length may not be an acceptable prognostic factor for carcinoma oesophagus. Further randomized multicentre studies might bring more evidence to practice of medicine. 


\section{REFERENCES}

1. Lindsey A Torre, Freddie Bray, Rebecca LS, et al. Global cancer statistics, 2012. CA Cancer J Clin 2015;65(2):87108.

2. SEER 18 2006-2012, All Races, Both sexes by SEER Summary stage 2000 .

http://seer.cancer.gov/statfacts/html/esoph.html

3. Stein HJ, Feith M, Bruecher BL, et al. Early oesophageal cancer: pattern of lymphatic spread and prognostic factors for long-term survival after surgical resection. Ann Surg 2005;242(4):566-73, discussion 573-5.

4. Edge SB, Byrd DR. AJCC cancer staging manual. New York, NY: Springer 2010; $7^{\text {th }}$ edn:103-15.

5. Tajima Y, Nakanishi Y, Ochiai A, et al. Histopathologic findings predicting lymph node metastasis and prognosis of patients with superficial oesophageal carcinoma: analysis of 240 surgically resected tumours. Cancer 2000;88(6):1285-93.

6. Puja Gaur, Boris Sepesi, Hofstetter WL, et al. Endoscopic oesophageal tumour length: a prognostic factor for patients with oesophageal cancer. Cancer 2011;117(1):63-9.
7. Arife Zeybek, Abdullah Erdogan, Gülkesen KH, et al. Significance of tumour length as prognostic factor for oesophageal cancer. Int Surg 2013;98(3):234-40.

8. Camille Asher Berriochoa, Damiel Hibbard, Mary Morco, et al. Tumour length as a prognostic factor in oesophageal cancer management. J Radiat Oncol 2015;4(1):71-7.

9. Sai Yendamuri, Stephen G Swisher, Correa AM, et al. Oesophageal tumour length is independently associated with long-term survival. Cancer 2009;115(3):508-16.

10. Feng JF, Huang Y, Zhao Q, et al. Tumour length in elderly patients with oesophageal squamous cell carcinoma: is it a prognostic factor? Ups J Med Sci 2013;118(3):145-52.

11. Seyed Kazem Mirinezhad, Amir Ghasemi Jangjoo, Seyednejad F, et al. Impact of tumour length on survival for patients with resected oesophageal cancer. Asian Pac J Cancer Prev 2014;15(2):691-4.

12. Wang BY, Goan YG, Hsu PK, et al. Tumour length as prognostic factor in oesophageal squamous cell carcinoma. Ann Thorac Surg 2011;91(3):887-93. 